\title{
Yapay Sinir Ağları, Destek Vektör Makineleri ve AdaBoost Algoritması ile Araç Sınıflandırmasının Değerlendirilmesi
}

\author{
Seda Kul ${ }^{1 *}$, Ahmet Sayar ${ }^{2}$

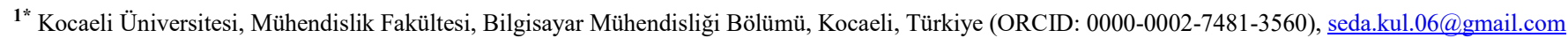 \\ ${ }^{2}$ Kocaeli Üniversitesi, Mühendislik Fakültesi, Bilgisayar Mühendisliği Bölümü, Kocaeli, Türkiye (ORCID 0000-0002-6335-459X), ahmet.sayar@kocaeli.edu.tr
}

(International Symposium on Multidisciplinary Studies and Innovative Technologies (ISMSIT) 2021 -21-23 October 2021)

(DOI: 10.31590/ejosat.1023889)

ATIF/REFERENCE: Kul, S., Sayar, A., (2021). Yapay Sinir Ağları, Destek Vektör Makineleri ve AdaBoost Algoritması ile Araç Sınıflandırmasının Değerlendirilmesi. Avrupa Bilim ve Teknoloji Dergisi, (29), 299-303.

\section{Öz}

Trafik yönetimi ve bilgi sistemlerinin trafik akışını doğru sağlayabilmesi için çeşitli sensörler ve kameralar kullanarak trafik hakkında bilgi edinmesi hayati önem taşımaktadır. Bu bağlamda video kameralar son yıllarda trafik gözetim ve kontrolünde yaygın ve aktif olarak kullanılmaya başlanmıştır. Bu çalışmada araçlar boyutlarına göre üç kategoriye ayrılarak sınıflandırılmıştır. Oluşturduğumuz trafik video görüntüleri üzerinde Yapay Sinir Ağları, Destek Vektör Makineleri ve Adaboost sınıflandırıcıları ile eğitim gerçekleştirilmiş ve performansları karşılaştırılmıştır. bölge özellikleri.

\section{Evaluation of Vehicle Classification with Artificial Neural Networks, Support Vector Machines, and AdaBoost Algorithm}

\begin{abstract}
It is vital for traffic management and information systems to obtain information about the traffic using various sensors and cameras in order to provide the traffic flow correctly. In this context, video cameras have been widely and actively used in traffic surveillance and control in recent years. In this study, vehicles were classified into three categories according to their sizes. Training was carried out with Artificial Neural Networks, Support Vector Machines and Adaboost classifiers on the traffic video images we created and their performances were compared.
\end{abstract}

Keywords: Vehicle classification, Intelligent traffic management, Neural Networks, Support Vector Machines and Adaboost, Binary image region properties.

\footnotetext{
*Sorumlu Yazar: seda.kul.06@gmail.com
} 


\section{Giriş}

Son y1llarda akıllı trafik yönetimi [1, 2] özelikle trafik gözlemi ve denetiminde video kameralarının kullanımı çok yaygınlaşmış ve aktif olarak kullanılmaktadır. Görüntü işleme tabanlı video izlemeye dayalı trafik sistemleri yardımıyla plaka tanıma [3], araç sayısı bulma [4], trafik yoğunluğu tespiti [5], araç hızı hesaplanması [6], şerit ihlalleri [7] ve araç sınıflandırma [8] gibi birçok çalışma yapılabilmektedir.

Araç sınıflandırma; otoyolları kullanan araç sınıflarının yüzdelerini elde etmek, asfalt kalınlığını belirlemek ve farklı özelliklere göre (büyüklük, renk vs.) video görüntüleri içinde araç araması yapmak açısından önemlidir. Mevcut durumda bu bilgiler, video kameralarından yararlanılarak insan gözlem gücü ile elde edilmektedir. Araç sınıflandırmada otomatik bir sistemin kullanılması, insan operatörlerinin kullanımını ortadan kaldıracak ve buna bağlı maliyet azalacaktır.

Akıllı araç yönetim sistemlerinde, sisteme kayıtlı kullanıcılara istedikleri özelliklere sahip araçlara ait bilgi/görüntülerin gerçek zamanlı olarak aktarılması da son derece önemlidir. Örneğin bir kullanıcı sadece küçük sınıfa ait araçların (sedan gibi) görüntülerini almak isteyebilirken başka bir kullanıcı büyük sınıfa ait (kamyon gibi) araçların görüntüleri üzerinde çalışmak isteyebilir. Bu da ilgilenilen görüntüler üzerinde yapılan herhangi bir araştırma işlemini hızlandıracaktır.

Çalışma kapsamında araç görüntülerinin farklı sınıflandırıcılar ile araba, orta sınıf araç ve büyük sınıf araç olmak üzere üç sınıfa ayrılması ve bunların performans metriklerinin değerlendirilmesi üzerinde durulmuştur.

Gerçekleştirilen yaklaşımın alt yapı planlaması, trafik yönetimi ve trafik suçları ile mücadele gibi farklı alanlara fayda sağlayacağı göz ardı edilemez. Sistemin etkinliği diğer araştırmacılar tarafından oluşturulmuş veri setleri üzerinde test edildiği gibi kendi oluşturduğumuz video görüntüleri üzerinde de sınanmıştır.

Makalenin geri kalan kısmı şu şekilde organize edilmiştir. II. bölümde, araç sınıflandırma ile ilgili çalıșmalara yer verilecektir. III. bölümde, araç görüntülerinin sınıflandırılması ile ilgili önerilen yaklaşımın alt adımları detaylıca açıklanacaktır. IV. bölümde kendi oluşturduğumuz veri seti üzerinde gerçekleştirilen sınıflandırma başarımları değerlendirilecektir. Son bölümde ise sonuçlara yer verilecek, gelecek çalışmalar sunulacaktır.

\section{Araç Sınıflandırma Literatür Taraması}

Son yıllarda akıllı ulaşım sistemleri ve akıllı trafik yönetim uygulamaları, çeşitli devlet kuruluşları veya özel şirketler tarafindan üzerinde titizlikle durulan konulardandır. Görüntü işleme yöntemleri de bu yazılım ve uygulamaları geliştirirken kullanılan temel algoritmalardandır. Görüntü işleme temelli araç sınıflandırma sistemleri üzerinde literatürde birçok çalışma vardır. Bu çalışmada ise kent güvenlik sistemlerinden elde edilen trafik videolarından elde edilen görüntüler, içeriklerine göre ilgili konuya (büyüklük) bölütlenerek o konuya ait kanaldan yayımlanacaktır. $\mathrm{O}$ kanala kaydolan istemciler görüntünün sadece ilgili olan kısımlarını alacaklar. Bu şekilde a ̆̆ trafiği azalacak, görüntü işleme uygulamalarında ölçekleme ve performans problemlerine çözüm sunulmuş olacaktır.
Literatüre sınıflandırma ve nesne saptama üzerine araştırmacılar birçok çalışma kazandırmışlardır. Araç tespit ve kategorilendirmesi diğer konulara göre daha az işlenmiş bir konudur. Messelodi ve diğ. [9] araç tespiti için Kalman filtresi ve Gauss dağılımı tabanlı bir yaklaşım önermiş ve sistemlerinin performansını \%92,5 doğruluk olarak vermişlerdir. Buch ve diğ. [10] ise üç boyutlu modele dayalı bir sınıflandırma gerçeklemişler ve $\% 90,4$ anısama, \%87,9 hassasiyet ile sistemin performansını göstermişlerdir. Morris ve Trivedi [11, 12] Gauss tabanlı araç tespiti yapmışlar temel bileşen analizi ve doğrusal ayırtaç analizleriyle özellik vektöründe boyut indirgeme gerçekledikten sonra K-yakın komşu sınıflandırması ile de araçların sınıflarını tespit etmişlerdir. Gandhi ve Trivedi [13] de yönlü eğim histogramı özelliklerinin kullanıldığı araç içi bir sistem sunmuşlar, destek vektör makineleri ile sınıflandırılma yapmışlardır. Demet ve Gözde [14] ise otoyola ait herhangi bir bilgiye ve kamera parametre kalibrasyonuna ihtiyaç duymadan öğrenmeye dayalı bir sınıflandırma yöntemi sunmuşlardır. Önerilen yöntemi iki farklı video üzerinde test etmişler. İlk videoda sadece HOG özellikleri kullandıklarında \%79.7 doğruluk, HOG ile beraber imge özellikleri kullandıklarında \% 80.6 doğruluk elde etmişlerdir. İkinci videoda ise sadece HOG özellikleri kullandıklarında \%91.2 doğruluk, HOG ile beraber imge özellikleri kullandıklarında \%96.4 doğruluk elde etmişlerdir. Ghada ise [15] yapmış olduğu çalışmada araç tipi sınıflandırmak için geometrik ve görünüm özelliklerini beraber kullanmıştır. Katmanlı bir sınıflandırma yapısı düşünülerek ilk katmanda araçlar küçük, orta ve büyük kategorisine ayrılmış, ikinci katmanda ise orta büyüklükteki araçlar kendi içinde tekrar sınıflandırılmıştır. Sınıflandırıcı olarak SVM seçilmiştir. Yapılan testler neticesinde ilk katmandaki sınıflandırma işleminin başarısı genişlik ve yükseklik özelliklerine göre (\%96.7) ve sadece SIFT'e göre (\%95.8) en yüksektir. İkinci katmandaki başarı ise yalnız SIFT (\%89.6) kullanımında en yüksektir. Dong ve diğ. [16] araçların önden görünümlerini yarı denetmenli yapay sinir ağı ile sınıflandırmışlardır. Yapay sinir ağı girdi olarak aldığı her bir görüntü için olasılıksal bir sonuç döndürmektedir. Gündüz çekilmiş görüntüler üzerinde $\% 95.7$, gece çekilmiş görüntüler üzerinde ise \%88.8 sınıflandırma başarısı yakaladıklarını belirtmişlerdir. Literatürdeki çalışmalar ile karşılaştırıldığında önerilen yaklaşımda farklı özellikler (SIFT, SURF, HOG, LBP) bir arada kullanılmış ve konu tabanlı olarak gerçek zamanlı sinıflandırılan görüntülerin istemcilere servis edilmesi sağlanmıştır. Her bir imge özelliğinin farklı sınıflandırma algoritmaları için doğruluk başarımları değerlendirilecektir

\section{Araç Görüntülerini Sınıflandırma}

Bu bölümde araçların küçük, orta ve büyük olarak sınıflandırılmasına dayalı mimarinin alt adımları verilecek olup IV. bölümde performans testleri üzerinde durulacaktır.

\section{1. Ön plan ve Arka plan Çıkarımı}

Aracın, görüntü üzerinden ayrılıp farklı bir nesne olarak belirlenmesi için BGS (background subtraction) kütüphanesinden faydalanılmıştır. Sınıflandırma aşaması için araca ait öznitelikler belirlenmiş ve veri setinde bulunan araçlar için çıkarılmıştır.

Arka plan tespiti, kamera tarafindan kaydedilen görüntü dizisinden, hareketli nesnelerin arka plandan çıkarılmasıdır [17]. Bu görev için, Andrew Sobral'ın [18] BGS algoritması içeren açık kaynaklı kütüphanesi kullanılmıştır. $\mathrm{Bu}$ noktada amaç, algoritmaların birbirlerine karşı avantajlarını ve dezavantajlarını tespit ederek proje için uygun olan BGS algoritmasını seçmektir. 
Andrew Sobral'ın makalesinde yer alan her grup içerisinde en iyi olan beş algoritma değerlendirildi.

Gerçek zamanlı arka plan çıkarımı metodu seçimi için BMC 111 [19], Changedetection Highway ve Changedetection Low frame rate turnpike veri setleri [20] üzerinde en iyi beş algoritma denenmiş gerçek zamanlı sistemler için "Adaptive Background Learning” algoritması seçilmiştir [21]. Hareket halindeki araçların tespiti için ön plan-arka plan çıkarımı gerekmektedir. Bu amaçla Gauss dağılımlarının karışımı MOG yönteminden yararlanılmıştır [22]. Elde edilen ikili haldeki görüntülerdeki hareketli kısımları belirginleştirmek ve gürültüleri azaltmak için açma-kapama gibi morfolojik işlemlerle bağlı bileşen analizi yapilmıştır.

\section{2. Özellik Vektörünün Oluşturulması}

Sınıflandırma aşamasındaki özellik vektöründe kullanılmak üzere elde edilen imge bölgeleri için üç farklı kategoride (geometrik tabanlı, görünüm tabanlı ve ikili imge özellikleri) özellik çıkarılmıştır. Burada geometrik tabanlı özelliklerden kasıt; en, boy, yüksekliktir. Görünüm tabanlı özellikleri ise ölçek bağımsız özellikler (SIFT) [23] ve hılandırılmış gürbüz özellikler (SURF) [24] özellikler oluşturmaktadır. İkili nesnelere ait özellikler ise imge alanı, en/boy ve bunların oranı, imgenin ana ve ikincil eksen uzunluklarından oluşmaktadır.

\subsection{Sınıflandırma Algoritmaları}

Bir önceki adımda oluşturulan özellik vektörleri sınıflandırma yöntemlerine girdi olacaktır. Sınıflandırma aşamasında öğrenmeye dayalı sınıflandırma metodu olan lineer destek vektör makineleri, yapay sinir ağları ve AdaBoost kullanılmıştır. Sonuç olarak hareketli araç görüntüleri küçük sınıf (araba gibi), orta sınıf araç (kamyonet gibi) ve büyük sınıf araç (kamyon) gibi sınıflandırılmıştır. Sınıflandırma için veri setinin bir kısmı (\%75 gibi) eğitim için geri kalan kısım da test işlemi için kullanılmıştır. Sınıflandırma başarısı; doğruluk (accuracy), anısama (recall), ve hassasiyet (precision) parametrelerine göre takip eden bölümde değerlendirilmiştir.

\section{Performans Testleri}

$\mathrm{Bu}$ bölümde oluşturduğumuz veri seti hakkında bilgi verilecektir. Daha sonra bu veri seti üzerinde gerçekleştirilen araç sinıflandırma performans testleri üzerinde durulacaktır.

\subsection{Veri Seti Tanıtımı}

Çalışmada kendi veri setimizi ve zemin gerçeği (ground truth) görüntülerimizi oluşturmak adına çekim gerçekleştirildi. Çekim sonunda 1920 x 1080 boyutunda 3071 çerçeve elde edildi, çerçevelerin ground truth görüntüleri oluşturuldu. Tablo 1'de elde edilen veri seti ve bunlara ait ground truth görüntüler verilmiştir. Veri seti (http://ipcv.kocaeli.edu.tr/wp/) web sayfasında akademik çalışmalar için herkes tarafından erişilebilir hale getirilecektir.
Tablo 1. Oluşturulan veri setinden bir kesit

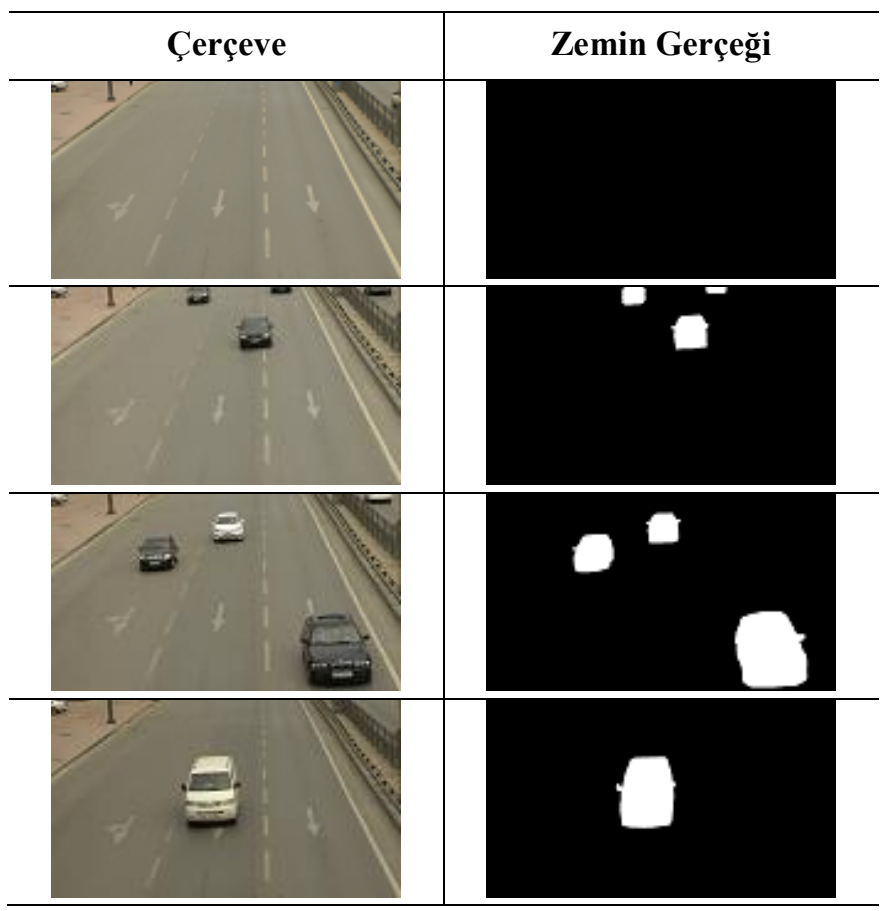

Araçların sınıflandırılmasında kullanılacak görüntülerden öznitelik vektörü elde edildi. Vektör elde edim aşamasında görüntünün en uzak kenarında bulunan büyük sınıflı aracın küçük sınıflı araç ile karıştırılmaması için, Şekil 1'de gösterildiği üzere referans çizgisine bağlı araçlar seçildi. Veri seti 3071 görüntüden oluşmaktadır fakat referans çizgisine bağlı veri seti 185 görüntüye sahiptir.

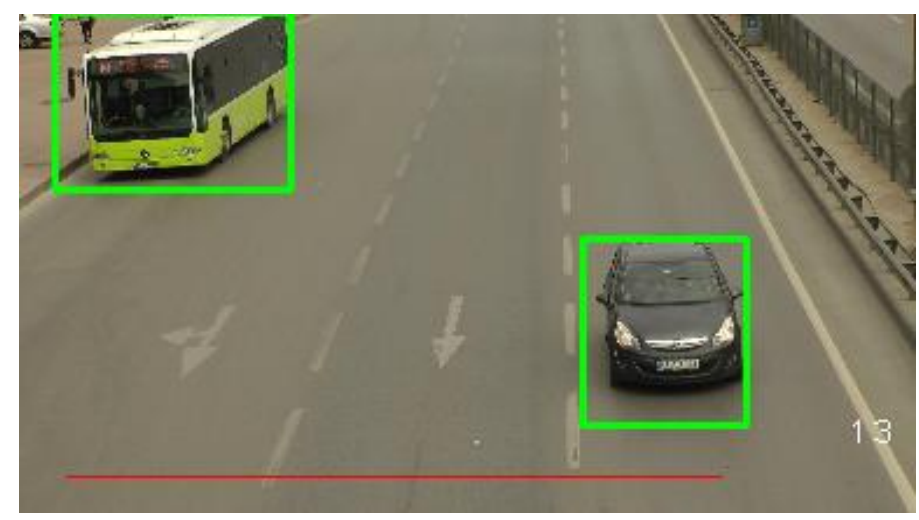

Şekil 1. Referans çizgisi gösterimi

Veri setinde Tablo 2'de gösterildiği üzere toplamda 176 olmak üzere 124 küçük sınıf, 42 orta sınıf ve 8 büyük sınıf araç mevcuttur.

Tablo 2. Araç tipine göre dă̆ılım

\begin{tabular}{cc}
\hline Araç Tipi & Sayısı \\
\hline Otomobil & 122 \\
Otobüs & 3 \\
Minibüs & 13 \\
Hafif Ticari & 22 \\
Kamyonet & 4 \\
Tir & 8 \\
Motor & 2 \\
\hline
\end{tabular}


Sınıflandırma aşamasında, görüntüler üzerinden araçların özellikleri elde edilmiştir. Toplamda 8 özellik araçların sınıflandırılması için kullanılmıştır. Özelliklerin ikili olarak sınıflar üzerindeki dağılımı Șekil 2'de verilmiştir.

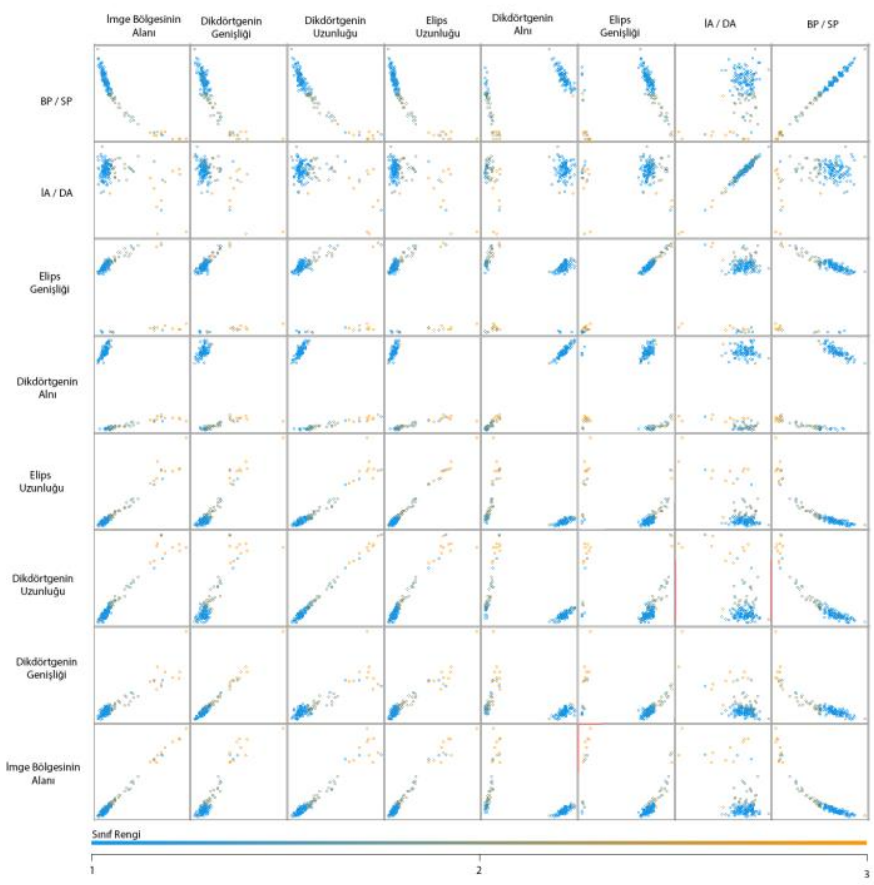

Şekil 2. Özelliklerin dăğllımı

Araçlara ait imge bölgesi çıkarıldıktan sonra, sırası ile çıarılan özellikler:

- İmge bölgesinin alanı hesaplanır

- İmge bölgesi bir dikdörtgen ile çevrelenir

- Dikdörtgenin uzun ve kısa kenarları ölçülür

- Dikdörtgenin alanı hesaplanır

- İmge bölgesi bir elip ise çevrilir

- Elipsin kısa kenarı ve uzun kenarı ölçülür

- İmge bölgesi alanı, dikdörtgen bölgesi alanına oranlanır.

* İA / DA = İmge Bölgesi Alanı / Dikdörtgen Bölgesi Alanı

- İmge bölgesinde Bulunan Beyaz Piksel Sayısı, Siyah Piksel Sayısına Oranlanır. *BP / SP = Beyaz Piksel Sayıs1 / Siyah Piksel Sayıs1

\subsection{Sinıflandırma}

Yapay sinir ağları, biyolojik nörondan esinlenerek geliştirilmiş öğrenme modelidir. Nöron temel yapıtaşını oluşturur. $\mathrm{Bu}$ çalışmada YSA modelinin, Şekil 3'te gösterildiği üzere YSA'da 8 nöronlu (özellik) giriş katmanu, 20 nöronlu bir gizli katman ve 3 nöronlu çıkış katmanı bulunmaktadır.

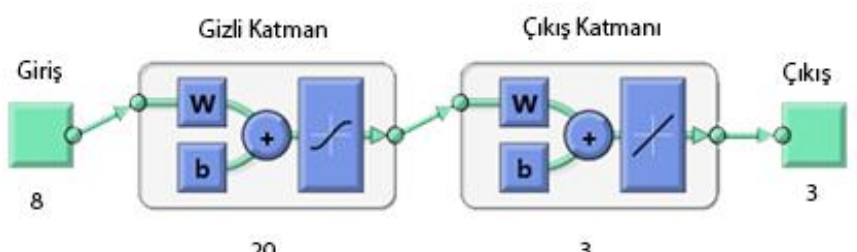

Şekil 3. Yapay sinir ă̆ı modeli
YSA, eğitim aşamasında yapay sinir ağı en iyi sonucu 202 epoch da elde etmiştir. Ortalama karesel hata (mse), 0.079184 elde edilmiştir. Eğitim aşamasında \%95,7 'lik doğruluk oranı ile, geçerleme (validation) aşamasında \%83,3 doğruluk ile ve test aşamasında $\% 87.5$ doğruluk ile çalışmıştır.

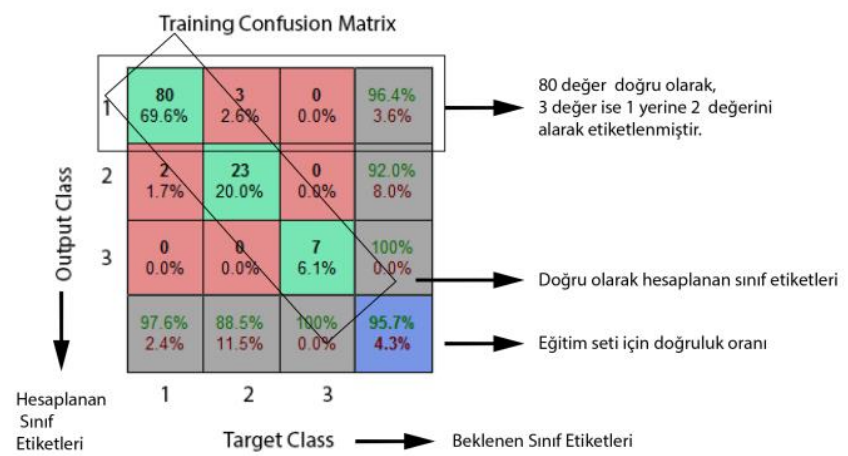

Şekil 4. Karışıllık matrisi

DVM, yapısal risk en küçükleme prensibine göre çalışan dış bükey optimizasyona dayalı bir makine öğrenmesi modelidir. Söz konusu yöntem veriye ilişkin herhangi bir ön bilgiye ihtiyaç duymadığı için dağılımdan bağımsız bir yöntemdir.

DVM'e ait hassasiyet ve anımsama değerleri Tablo 3'te verilmiştir.

Tablo 3. Precision ve Recall Değerleri

\begin{tabular}{lll}
\hline Sınıflar & Hassasiyet & Çağrışım \\
\hline Küçük Sınıf & 80.7 & 97.4 \\
Orta Sınıf & 82.4 & 40 \\
Büyük Sınıf & 100 & 50 \\
\hline
\end{tabular}

SVM, \%81.6 doğruluk ile sınıflandırma yapmaktadır.

AdaBoost algoritması, eğitim veri seti üzerinden dağglıma bağlı olarak düşük hatalı hipotez üretmeye çalışmaktadır.

Tablo 4'te Adaboost'a ait karışıklık matrisi verilmiştir.

Tablo 4.AdaBoost karışıklık matrisi

\begin{tabular}{c|l|l|l|l}
\cline { 3 - 4 } \multicolumn{2}{c}{} & \multicolumn{3}{c}{ Tahmin Edilen Durum } \\
\cline { 3 - 5 } \multicolumn{2}{c}{} & $\begin{array}{l}\text { Küçük } \\
\text { Sinıf }\end{array}$ & $\begin{array}{l}\text { Orta } \\
\text { Sinıf }\end{array}$ & $\begin{array}{l}\text { Büyük } \\
\text { Sinıf }\end{array}$ \\
\hline \multirow{3}{*}{$\begin{array}{l}\text { Gerçek } \\
\text { Durum }\end{array}$} & Küçük Sinıf & 30 & 4 & 0 \\
\cline { 2 - 5 } & Orta Sinıf & 2 & 9 & 0 \\
\cline { 2 - 5 } & Büyük Sınıf & 1 & 0 & 2 \\
\hline
\end{tabular}

Sinıflandırıcı, \%85.416 doğruluk ile sinıflandırma yapmaktadır.

\section{Sonuç}

Geliştirilen araç büyüklük (küçük, orta ve büyük) sınıflandırma alt yapısının aşağıdaki faydaları sağlaması beklenmektedir:

- Kritik ve stratejik kararları zamanında ve doğru almasına imkân sağlanacaktır. 
- Video görüntüleri üzerinden nesne tanımaya dayalı ölçeklenebilir dağıtık bir mimari altyapısının geliştirilmesi sağlanacaktır.

- Önerilen sistem ile manuel olarak işlem yapan operatörlerin etkinliği azaltılacak ve gerçek zamanlı videolardan nesne tanımada daha doğru sonuçlar elde edilmesi sağlanacaktır. Operatör tüm gün boyu kamera görüntüsünü takip etme zorunda kalmayacak, sistemde ilgili olduğu araç ya da nesne ekrana düştügünde uyarılarak operatörün dikkat problemlerini ortadan kaldırarak daha az yorulmasına neden olacaktır. İlgili olan kısmi görüntü operatöre gerçeğe yakın zamanda sunulacaktır.

- Son kullanıcılar farkı özelliklere göre (sınıf-büyüklük) arama kriteri belirleyebilecek ve belirli konulara kaydolan kullanıcılara gelen görüntüler üzerinde daha az arama uzayında arama ve işlem yapmak zaman tasarrufu sağlayacaktır.

İleride son kullanıcıların farkı özelliklere göre (renk, sınıfbüyüklük, hız) arama kriterlerini belirleyebilmesi (hiyerarşik konu olarak) ve belirli konulara (topic based pub/sub model) kaydolan kullanıcılara gelen görüntüler üzerinde daha az arama uzayında arama ve işlem yapması sağlanması üzerinde durulacaktır.

\section{Kaynakça}

Kul, S., Eken, S., \& Sayar, A. (2017). Distributed and collaborative real-time vehicle detection and classification over the video streams. International Journal of Advanced Robotic https://doi.org/10.1177/1729881417720782.

Systems.

Şentaş, A., Tashiev, İ., Küçükayvaz, F. et al. Performance evaluation of support vector machine and convolutional neural network algorithms in real-time vehicle type and color classification. Evol. Intel. 13, 83-91 (2020). https://doi.org/10.1007/s12065-018-0167-z.

C. Gou, K. Wang, Y. Yao, Z. Li, "Vehicle License Plate Recognition Based on Extremal Regions and Restricted Boltzmann Machines," IEEE Transactions on Intelligent Transportation Systems, 17(4): 1096-1107, 2016.

N. Miller, M. A. Thomas, J. A. Eichel, A. Mishra, "A Hidden Markov Model for Vehicle Detection and Counting," IEEE 12th Conference on Computer and Robot Vision 269 - 276, 2015.

Shrikant Fulari, Ajitha Thankappan, Lelitha Vanajakshi \& Shankar Subramanian (2019) Traffic flow estimation at error prone locations using dynamic traffic flow modeling, Transportation Letters, 11:1, 43-53, DOI: 10.1080/19427867.2016.1271761S. C. Subramanian, M. Panda, "Performance Comparison of Filtering Techniques for Real Time Traffic Density Estimation under Indian Urban Traffic Scenario," IEEE 18th International Conference on Intelligent Transportation Systems, pp. 1442-1447, 2015.

H. Im, B.Hong, S. Jeon, J. Hong, "Bigdata analytics on CCTV images for collecting traffic information," 2016 International Conference on Big Data and Smart Computing, pp. 525-528, 2016.

R. Marikhu, J. Moonrinta, M. Ekpanyapong, M. Dailey, S. Siddhichai, "Police Eyes: Real world automated detection of traffic violations," 10th International Conference on Electrical Engineering/Electronics, Computer,
Telecommunications and Information Technology, pp. 1-6, 2013.

H.C. Karaimer, I. Cinaroglu, Y. Bastanlar, "Combining ShapeBased and Gradient-Based Classifiers for Vehicle Classification," IEEE 18th International Conference on Intelligent Transportation Systems, pp. 800-805, 2015.

S. Messelodi, C.M. Modena, M. Zanin, "A computer vision system for the detection and classification of vehicles at urban road intersections", Pattern Analysis \& Applications, 8(12):17-31, 2005.

N. Buch, J. Orwell, S.A. Velastin, "Detection and classification of vehicles for urban traffic scenes", 5th International Conference on Visual Information Engineering, pp.182-187, 2008.

B. Morris, M. Trivedi, "Robust classification and tracking of vehicles in traffic video streams", In Intelligent Transportation Systems Conference. ITSC '06. IEEE, pp.1078-1083, 2006.

B. Morris, M. Trivedi, "Improved vehicle classification in long traffic video by cooperating tracker and classifier modules", In AVSS '06: Proceedings of the IEEE International Conference on Video and Signal Based Surveillance, page 9, Washington, DC, USA. IEEE Computer Society, 2006.

T. Gandhi, M.M. Trivedi, "Video based surround vehicle detection, classification and logging from moving platforms: Issues and approaches", In Intelligent Vehicles Symposium, pp. 1067-1071, 2007.

D. Demet, B.A. Gözde, "Hareket Halindeki Araçların Sinıflandırılması", 21st Signal Processing and Communications Applications Conference (SIU), pp. 1-4, 2013.

S.M. Ghada, "Vehicle Type Classification with Geometric and Appearance Attributes", World Academy of Science, Engineering and Technology International Journal of Civil, Structural, Construction and Architectural Engineering 8(3): 273-278, 2014.

Z. Dong, Y. Wu, M. Pei, Y. Jia, "Vehicle Type Classification Using Semi-Supervised Convolutional Neural Network", IEEE Transactions on Intelligent Transportation Systems, 16(4): $2247-2256,2015$.

S. Kul, S. Eken, A Sayar, "Video Gözetleme Sistemlerinde Terk Edilmiş Nesne Saptamak için Servis Odaklı Uyarı Sistemi," 23nd Signal Processing and Communications Applications Conference, 911-914, 2015.

A. Sobral, A. Vacavant "A comprehensive review of background subtraction algorithms evaluated with synthetic and real videos," ComputerVision and Image Understanding ELSEVIER, vol. 122, pp. 4-21, May 2014.

BMC veri seti, http://bmc.iut-auvergne.com/?page_id=24

Changedetection veri setleri, http://changedetection.net/

S. Kul, S. Eken, A. Sayar, ""Evaluation of Real-time Performance for BGSLibrary Algorithms: A Case Study on Traffic Surveillance Video," IEEE 6th International Conference on IT Convergence and Security, 2016.

Z. Zivkovic, "Improved Adaptive Gaussian Mixture Model for Background Subtraction", Proceedings of the 17th International Conference on (ICPR'04), pp. 28-31, 2004.

D.G. Lowe, "Distinctive image features from scale-invariant keypoints," International journal of computer vision, 60, 91 110, 2004.

H. Bay, T. Tuytelaars, L. Van Gool, "Surf: Speeded up robust features”, ECCV, Springer, 404-417, 2006. 